\title{
Physical geographic research in transitional environments Introduction to the special issue
}

\section{Nikolaus J. Kuhn, Basel}

Modern physical geographic research focuses on dynamic interaction between surface and climate, especially the impact of climate change on spatial and temporal patterns of surface processes and landscape development (e.g. Goudie \& Stokes 2007). On a continental scale, the effects of climatic gradients on surface processes and landforms are well understood. However, the relatively small changes of rainfall and temperatures predicted for the next 100 years produce a highly variable range of geomorphic responses in landscapes altered by human activities. Issues such as the «Missing Land Carbon» (INTERGovernMENTAL Panel on Climate Change, IPCC, 2007) illustrate the research needs on small to medium-scale landscape systems and their reaction to environmental change. Our understanding of the impact environmental change will have on surface processes and landscape development is limited in two ways. Firstly, climate and land use are in a quasi-permanent state of transition, which affects both the nature and the spatial and temporal patterns of surface processes. Secondly, over time, soils and vegetation will be altered in response to changing processes, generating themselves a feedback on surface processes. In the $21^{\text {st }}$ century, continuing climate change, probably also accompanied by further land use change, is likely to create environments characterised by a permanent state of transition. Such «Transitional Environments» therefore cannot still be considered to be in a dynamic or metastabile equilibrium with their external controlling factors. Therefore, the impact of changing land use and climate on surface processes and landscape development cannot be addressed, as is commonly done, by simply linking future climate to runoff ratios and erosion rates observed under current surface conditions. This approach ignores the dynamic nature of surface-climate interaction. Currently, the reactions of soil and vegetation to environmental change and their feedback on system functions and functioning, e.g. ecohydrology and ecogeomorphology (e.g. ArBEL et al. 2005; KuHN 2007), are of particular relevance for physical geographic research in particular, but also for environmental sciences, politics and economics in general.

The selection of studies published in this issue of Geographica Helvetica illustrates issues for and approaches to physical geographic research in tran- sitional environments. NAOMI Holmes shows how environmental reconstruction on Iceland can contribute towards greater understanding of the complex interaction between climate, land cover and surface processes. Milica Kasanin-Grubin's analysis of climate change impacts on badlands illustrates how seemingly small changes in external factors can alter surface processes and trigger a new direction of landscape development. While still relatively simple in nature, badlands can serve as useful analogue models for larger, more complex geomorphic and landscape systems. RichARD GuTHRIE's and KENDRICK BROWN's study of landslides on Vancouver Island indicates how even in complex and dynamic landscapes, a good understanding of surface processes and the controlling factors for mass wasting events help reduce complexity and support the assessment of past and future system reaction to change. The final two papers continue the theme of impact assessment. HAO CHEN, Abdelkader El Garouani and Laurence Lewis show how the initially simple stochastic approach of the Universal Soil Equation has been developed and modified in the past 20 years and can now be used to assess the multiple risks of soil erosion in a changing landscape in a land like Morocco, which is characterised by high data uncertainty. Finally, NiKOLAus KuHN and HongLei ZHU present a combined field measurement and GIS-based modelling approach for estimating the risks of runoff generation and routing during extreme events. The study focuses on slopes that until now were not considered to generate runoff even during extreme events and were for this reason not included in catchment-scale modelling. Their findings indicate that a better understanding of runoff generation and routing on slopes is essential for the management of risks associated with extreme events expected to characterise the $21^{\text {st }}$ century.

\section{References}

ArBeL, Y., YAIR, A. \& S. Oz (2005): Effect of topography and water repellent layer on the non-uniform development of planted trees in a sandy arid area. - In: Journal of arid environments 60, 1: 67-81.

Goudie, A. \& S. Stokes (2007): Environmental change through the Quaternary. - Cary, North Carolina: Oxford University Press.

Intergovernmental Panel on Climate Change (IPCC), Solomon, S., Qin, D., Manning, M., Marquis, M., Averyt, K., Tignor, M.M.B., Miller, Jr., H.L. \& Z. Chen (eds) (2007): Climate change 2007. The physical 
science basis. - Contribution of Working Group 1 to the Fourth Assessment Report of the Intergovernmental Panel on Climate Change. - Cambridge: Cambridge University Press.

KuHN, N.J. (2007): Erodibility of soil and organic matter: independence of organic matter resistance to interrill erosion. - In: Earth surface processes and landforms 32, 5: 794-802.

VILES, H. (ed.) (1988): Biogeomorphology. - Oxford: Basil Blackwell.

Prof. Dr. Nikolaus J. Kuhn, Department of Environmental Sciences, Institute of Geography/Physical Geography and Environmental Change, University of Basel, Klingelbergstrasse 27, CH-4056 Basel, Switzerland.

e-mail: Nikolaus.Kuhn@unibas.ch 